\title{
ANTROPOFAGIA, DISSIDÊNCIAS E NOVAS PRÁTICAS: O TEATRO OFICINA
}

\section{ANTHROPOPHAGY, DISSIDENCES AND NEW PRACTICES: OFICINA THEATER}

\author{
Marcelo de Troi ${ }^{1}$
}

Leandro Colling ${ }^{2}$

\section{RESUMO}

Na intenção de mapear a construção de novos saberes-poderes e de uma "metodologia indisciplinar antropofágica", a partir do Teatro Oficina Uzyna Uzona, dirigido por José Celso Martinez Correa, o artigo coloca a Universidade Antropófoga como uma precursora dos artivismos das dissidências sexuais e de gênero no Brasil.

Palavras-chaves: Artivismos. Estudos Queer. Teatro. Antropofagia. Teatro Oficina.

\footnotetext{
${ }^{1}$ Mestrando no Programa Multidisciplinar de Pós-Graduação em Cultura e Sociedade da Universidade Federal da Bahia, e pesquisador do grupo de pesquisa em Cultura e Sexualidade - CUS. De 1998 a 2000 foi membro do Teatro Oficina. E-mail: troi.marcelo@ufba.br.

${ }^{2}$ Doutor em Comunicação e Culturas Contemporâneas e professor permanente do Programa Multidisciplinar de Pós-Graduação em Cultura e Sociedade, da Universidade Federal da Bahia, onde coordena o grupo de pesquisa Cultura e Sexualidade (CUS). E-mail: leandro.colling @ gmail.com.
} 


\begin{abstract}
To intend to do a map construction of new power-knowledge and a "anthropophagy indisciplinary methodology" from the Oficina Uzyna Uzona Theater, directed by José Celso Matinez Correa, this article puts the Anthropophagite University as a percursor of the artivisms of sexual dissidence, identity and gender in Brazil.
\end{abstract}

Keywords: Artivisms. Queer Studies. Theater. Anthropophagy. Oficina Theater. 


\section{Introdução}

Nos últimos anos, o Brasil tem registrado o surgimento de diversos artistas e coletivos que, em suas produções artísticas, têm como um dos objetivos principais questionar e problematizar as normas de sexualidade e gênero. Na música, aparentemente, temos nomes que rapidamente se tornaram bem conhecidos nacionalmente, como Johnny Hooker, Liniker, Jaloo, Caio Prado, Rico Dalasam, As Bahias e a Cozinha Mineira, MC Xuxu e MC Linn da Quebrada. Na cena teatral destacam-se o Teatro kunyn (São Paulo), As travestidas (Fortaleza), Atelier voador e Teatro A queda (Salvador). Fora isso, uma profusão de coletivos diversos, com ênfase em performances, como $\mathrm{O}$ que você queer? (Belo Horizonte), Cena queer (Salvador), Anarcofunk (Rio de Janeiro), Revolta da lâmpada (São Paulo), Selvática ações artísticas (Curitiba), Cabaret drag king (Salvador), Coletivo coiote (nômade), Seus putos (Rio de Janeiro). A lista poderia ser bem mais longa.

A emergência desses artistas e coletivos artivistas pode ser explicada por várias razões. Eis algumas: o espantoso crescimento dos estudos de gênero e sexualidade no Brasil, em especial os situados nas dissidências sexuais e de gênero; a ampliação do acesso às novas tecnologias e a massificação das redes sociais; a ampliação da temática LGBT na mídia em geral, em especial em telenovelas, filmes e programas de televisão; a emergência de diversas identidades trans e pessoas que se identificam como não-binárias em nosso país, além da valorização da fechação, da não adequação às normas (corporais e comportamentais) de meninos afeminados, mulheres lésbicas masculinizadas e outras várias expressões identitárias flexíveis que provocaram a abertura do fluxo antes mais rigidamente identitário. Mas talvez a mais importante das razões esteja exatamente na própria necessidade, autodeclarada ou não, de reagir frente ao quadro terrível no qual estamos inseridos, marcado pelo retorno e crescimento de um conservadorismo e do fundamentalismo religioso.

Assim como o ativismo queer pesquisado por Colling (2015) em outros países, essas pessoas artivistas brasileiras trabalham de formas diferenciadas, mas alguns aspectos as unem: 1) priorizam as estratégias políticas através de produtos culturais, pois entendem que os preconceitos nascem na cultura e que a estratégia da sensibilização via manifestações culturais é eficaz para produzir outros processos de 
subjetivação; 2) criticam a aposta exclusiva nas propostas dos marcos legais, em especial quando elas reforçam normas ou instituições consideradas disciplinadoras das sexualidades e dos gêneros; 3) explicam as sexualidades e os gêneros para além dos binarismos, com duras críticas às perspectivas biologizantes, genéticas e naturalizantes; 4) entendem que as identidades são fluidas e que novas identidades são e podem ser criadas, recriadas e subvertidas permanentemente; 5) rejeitam a ideia de que, para ser respeitado ou ter direitos, as pessoas devam abdicar de suas singularidades em nome de uma "imagem respeitável" perante a sociedade; 6) parecem mais conscientes da necessidade de interseccionar as suas lutas com vários outros marcadores sociais das diferenças, a exemplo de questões étnicas, de classes, gerações, níveis de escolaridade, capacidades corporais, territorialidades, etc.

Ao analisar o trabalho de algumas dessas artivistas, a pesquisadora Patrícia Lessa (2015) também apontou para algumas características. Uso intenso das novas tecnologias e redes sociais, produções não voltadas para espaços fechados ou museus, mas para as ruas, festas e outros espaços públicos de sociabilidade facilmente acessados, horizontalidade das produções e, fundamentalmente: "as artivistas, por meio dessas práticas, questionam o corpo, o sexo, e o modelo dessexualizado do contrato de casamento, propondo novas formas mais criativas de estar no mundo e de sentir a multiplicidade e o valor da liberdade para a vida" (Lessa, 2015, p. 222).

Como sabemos, a produção artística brasileira que problematiza as normas sexuais e de gênero não é absolutamente nova, a exemplo do grupo Dzi Croquettes (Cysneiros, 2014) e o cinema de Jomard Muniz de Britto (Sant'anna, 2016). E qual o papel do Teatro Oficina Uzyna Uzona $^{3}$ no que hoje estamos chamando de artivismos das dissidências sexuais e de gênero ${ }^{4}$ ? Começar a responder essa pergunta é o objetivo principal deste texto.

\footnotetext{
${ }^{3}$ Criado em 1958, o Oficina adota esse novo nome a partir de 1981. O Oficina é uma companhia teatral em processo permanente. Informações atualizadas sobre a companhia podem ser acessadas em www.teatroficina.com.br. Para uma linha do tempo do Oficina, de 1958-2008, ver http://www.teatroficina.com.br/menus/51/posts/258 Últimos acessos em 02/10/2016.

${ }^{4}$ Usamos a expressão "dissidências" em contraposição à ideia de "diversidade sexual e de gênero", já bastante normalizada, excessivamente descritiva e muito próximo do discurso da tolerância, ligada a uma perspectiva multicultural festiva e neoliberal que 
Nos apoiamos em Raposo para definir o que é artivismo:

Artivismo é um neologismo conceitual ainda de instável consensualidade quer no campo das ciências sociais, que no campo das artes. Apela a ligações, tão clássicas como prolixas e polêmicas entre a arte e política, e estimula os destinos potenciais da arte enquanto ato de resistência e subversão. Pode ser encontrado em intervenções sociais e políticas, produzidas por pessoas ou coletivos, através de estratégias poéticas e performativas (...). A sua natureza estética e simbólica amplifica, sensibiliza, reflete e interroga temas e situações num dado contexto histórico e social, visando a mudança ou a resistência. Artivismo consolida-se assim como causa e reivindicação social e simultaneamente como ruptura artística, de participação e de criação artística (Raposo, 2015, p. 4).

Os espetáculos do Oficina sempre suscitaram alguma discussão a respeito da quebra de paradigmas e de normas, seja nos anos de 1960, na luta contra a censura a partir de espetáculos que tentavam intervir diretamente no processo sociopolítico; seja nos anos de 1990, quando o grupo foi processado por um padre porque, durante uma cena de "Mistérios Gozosos", peça inspirada no poema "O santeiro do mangue" (1950), de Oswald de Andrade, simularam a liturgia da transubstanciação usando uma banana e seu potencial fálico; ou ainda em 2012, após a encenação de um ritual de decapitação do papa Bento XVI, no pátio da Pontifícia Universidade Católica, em São Paulo, quando dois atores do elenco foram ameaçados e processados.

Há 58 anos, o Oficina colhe o fruto e paga o preço por uma arte dissidente em um mundo controlado pelos padrões do cânone ocidental, da heteronormatividade (MISKOLCI, 2009), da cisgeneridade (VERGUEIRO, 2016), da hegemonia cristã e do neoliberalismo dominante no mercado do entretenimento. É uma das mais longevas companhias de teatro brasileiras, marcada por uma arte que se reinventa de tempos em tempos e por um fazer teatral, uma espécie de método interpretativo, que condensa não só os conhecimentos clássicos, mas, principalmente, uma experiência empírica, prática e cumulativa da companhia com as culturas brasileiras e outras artes do corpo, expressas muitas vezes em técnicas de disciplina orientais, na técnica da dança,

não explica como funcionam e se produzem as hierarquias existentes na tal "diversidade". 
nos dramaturgos e teóricos do teatro, na relação com o espaço do local da prática, e aqui falo da sede do grupo, desse ilê, ${ }^{5}$ dessa arquitetura, rastros e feixes para se compreender o trabalho da companhia.

Nesse espectro, dentro das influências europeias, russas, orientais e norte-americana, o Oficina bebeu inexoravelmente dos conceitos e do espírito de Oswald de Andrade e de sua Antropofagia. Um emaranhado, caminho de dramaturgias, temas e questões que levaram o grupo ao encontro de experiências novas de encenação, interpretação e discussões políticas para aqueles anos, em que a montagem de "O rei da vela", em 1967, se fixa como um dos marcos do movimento Tropicalista e do teatro brasileiro.

O texto de Oswald é de 1933 e foi publicado em 1937. Em maio de 1966, o teatro Oficina foi incendiado e procurava um texto para a inauguração da nova casa reformada (MARTINEZ CORREA, 1998). A peça emerge de um clima de radicalização política no país, com o recrudescimento da ditadura e maior controle de conteúdos culturais.

A montagem inédita de Oswald levou o grupo a descobrir um potencial quase "indomável":

O rei da vela foi uma desenfreada descoberta crítica do Brasil. Uma implacável e impiedosa revisão de valores que começava agredindo a nós mesmos, numa etapa de um vertiginoso processo de libertação de preconceitos e formação cultural colonizada. E terminava agredindo o público, inclusive a chamada elite intelectual e política, porque devolvia uma imagem crítica constituída basicamente de deboche e irreverência, não poupando mitos e estereótipos, investindo com fúria avassaladora contra códigos sacralizados de comportamento. Incorporando a postura livre e anárquica proposta por Oswald de Andrade, nosso espetáculo não conhecia limites em sua ânsia de questionar o que para nós significava a essência do processo ideológico e político tanto da direita quanto da esquerda (...) O rei da vela foi uma forma de realizar uma espécie de radiografia do país, revelando sua podridão, seu tecido interno canceroso e assim mesmo resistente, porque se renovava em nossa passividade e nosso ingênuo conformismo (PEIXOTO, 1982, p.72).

\footnotetext{
${ }^{5}$ Em yorubá, "terra", no sentido de local, chão no qual se vive e se exerce a prática. 
O depoimento de Fernando Peixoto, um dos atores da companhia na época, mostra o quanto a montagem mudaria o Oficina, com uma liberdade de criação que rompia limites, alçando José Martinez Corrêa a um dos maiores encenadores do país e talvez o mais inventivo. A emergência desse texto para aquele momento só pode ser explicada pela conexão profunda de Oswald com o Brasil arcaico e vítima da colonização, um "cadáver gangrenado", na qual o Oficina cumpria a tarefa de trazer tais questões à tona: "Nos empenhamos na autópsia", afirma Peixoto (1982).

Depois do elenco assistir a "Terra em transe", de Glauber Rocha, houve imediata identificação com aquela estética, levando todos ao estudo do pansexualismo oswaldiano: o axioma "transformar o tabu em totem", a partir das ideias de Freud, é uma das fórmulas proliferantes da antropofagia oswaldiana (NODARI, 2014, p.2). Outras influências foram o formalismo russo, o concretismo paulista dos irmãos Campos, "A revolução brasileira", de Caio Prado Jr, os estudos de Celso Furtado, Mário de Andrade e tantos mais.

"O rei da vela" iluminou o escuro da realidade brasileira. O espetáculo colocava artistas e intelectuais "na parede", levando todos a uma redefinição de seus trabalhos diante da leitura violenta da montagem, com um painel perturbador e crítico da vida nacional, dos mecanismos de poder, da manipulação e da dominação:

Sob ele encontramos o Oswald grosso, antropófago cruel, implacável, negro, apresentando tudo a partir de um cogito muito especial: "Esculhambo, logo existo". E esse esculhambar era o meio de conhecimento e de expressão de uma estrutura que a sua consciência captava como inviável. Pois essa consciência se inspirava numa utopia de um país futuro, negação do país presente, de um país desligado dos seus centros de controle externo e consequentemente do escândalo de sua massa marginal faminta. Para captar essa totalidade era preciso um super esforço. Tudo isso não cabia no teatro da época, apto somente para exprimir os sentimentos brejeiros lusobrasileiros. Era preciso então reinventar o teatro. E Oswald reinventou o teatro (MARTINEZ CORREA, 1998, p. 85).

A experiência de "O rei da vela" seria essencial para a criação desse "método" que, passados 40 anos, desemboca na conscientização de um 
trabalho extenuante dos atletores ${ }^{6}$ da companhia, também envoltos de maneira mística e mítica com aquele espaço território, com uma história de resistência que remonta ao tempo de quando o local era um centro espírita até a reforma revolucionária de Lina Bo Bardi. ${ }^{7}$

Em 1974, após a invasão do Teatro Oficina pela polícia, Zé Celso escreve: "Primeiro nos encontramos como médiuns, revivendo esses personagens em nós, no palco. Depois éramos nós mesmos na vida esses personagens. Éramos o próprio amor do escravo pela liberdade" (MARTINEZ CORREA, 1998, p.275). Essa nova prática libertária do anarquista coroado, em referência a Artaud (1991), esse saber-poder, está diretamente implicado com o espaço físico ao qual está circunscrito o teatro, e fundamentalmente implicado "no" e "pelo" outro. O Teato é a técnica teatral e corporal que vai dominar o espaço do pensamento rizomático nesse território. A primeira menção ao TE-ATO, neologismo que brinca com o verbo "atar" e "atuar", acontece em 1971 a partir da viagem UTROPIA (Utopia dos Trópicos) e traz em si a ideia de um teatro ativo que não deixa nem atores, nem espectadores, passivos. Em UTROPIA, o grupo viaja por 10 meses, do Rio de Janeiro a Manaus, passando por Salvador e Garanhus (onde o Bispo Sardinha foi devorado), fazendo uma pesquisa empírica com as culturas brasileiras.

Cria-se assim uma Poética de Relação, tal qual o espaço relacional das culturas atávicas e compósitas (GLISSANT, 2005), num processo de deseducação em termos de ressignificar a história colonial brasileira e toda sua potência. Tudo comunica e se "presenta" através dos tabus coloniais, da sociedade patriarcal brasileira, da antropofagia dos nativos, da influência dos negros da diáspora, da música popular. E na relação do corpo com este espaço arquitetônico único da Rua Jaceguai, no bairro do Bexiga, em São Paulo: as arquibancadas andaimes de teatro elisabetano $^{8}$, a pista-palco (que mede 1,5 × $20 \mathrm{~m}$ ), as projeções das

\footnotetext{
${ }^{6}$ Neologismo de ator e atleta, utilizado no grupo a partir da montagem de Os sertões, para indicar que o trabalho do ator se assemelha ao do atleta na sua dedicação absoluta ao ofício, um processo físico, de concentração e de repetição. Em 1999, uma leitura encenada de três das nove peças que compõem a obra completa Cacilda, para a reinauguração do TBC - Teatro Brasileiro de Comédia, durou 9 horas.

${ }^{7} \mathrm{O}$ teatro recebeu prêmio na Bienal de Arquitetura de Praga, em 2011, e foi eleito o melhor teatro do mundo pelo inglês The Guardian (11/12/2015): https://goo.gl/1RaALs. Último acesso em 10/12/2016.

${ }^{8} \mathrm{O}$ teatro elisabetano (1558-1625) se refere às obras dramáticas escritas e interpretadas durante o reinado de Isabel I de Inglaterra, sendo associado, tradicionalmente, à figura de William Shakespeare (1564-1616). Era um teatro aberto, popular e de má reputação, 
imagens (antes em televisores, hoje projetadas em todo o espaço arquitetônico), a parede de vidro que revela a cidade de São Paulo e seu Minhocão ${ }^{9}$, a cachoeira interna de canos de ferro, o teto móvel que revela o sol e as estrelas, o seu jardim com bananeira tropical e árvore que nasce dentro e atravessa para o lado de fora do edifício, e o seu entorno, um verdadeiro pomar, ameaçado pela especulação imobiliária e que tem sido ocupado por seus fundadores.

O Teatro Oficina tem sido há mais de três décadas símbolo da luta contra essa especulação. A área no entorno do Oficina já teve sinagoga e casas históricas que foram completamente demolidas. Mesmo como patrimônio tombado, o que garantiria a proteção no seu entorno, o Oficina sofreu com ameaças constantes do Grupo Sílvio Santos que pretendia construir um shopping no terreno ${ }^{10}$.

Essa posição de enfrentamento político, na luta por espaço e terra, similar às lutas empreendidas por posseiros, sem-tetos e sem-terras, também tem sido um dos motores desse fazer teatral. A disputa, que também é vista como luta antagônica dramatúrgica, une esses corpos e ressignifica o fazer teatral como potência criadora dessas contracenações que permeiam todas os processos em cena.

Nesse jogo que motiva a luta da companhia por um espaço seu como de direito, a partir das leis de patrimônio e tombamento, foi possível negociar e ocupar esse terreno em acordo com o grupo empreendedor por algum tempo, servindo de cenário para montagens. É nesse local que o Oficina já vislumbrou o ambiente perfeito para a aplicação de sua forma de atuação: a criação de um Teatro de Estádio, em sintonia com

marcado pela mistura de classes e com público ativo (OLIVA; MONREAL; 1990, p.141).

${ }^{9}$ O Elevado Costa e Silva é uma via para carros que liga a zona leste e oeste da cidade. Uma tragédia arquitetônica e urbanística para a cidade.

${ }^{10}$ No dia 26 de outubro de 2016, em mais um capítulo, os conselheiros do órgão de preservação do patrimônio Histórico, Artístico, Arqueológico e Turístico de São Paulo votaram contra a construção da Torre. Para cronologia sobre o tema ver: http://www.teatroficina.com.br/menus/45/posts/1025. Último acesso em 02/10/2016. Atualmente, nesse bairro, o edifício abandonado do Teatro Brasileiro de Comédia TBC, de onde surgiu o teatro moderno brasileiro, revela a situação calamitosa da Cultura e seu patrimônio. 
as ideias de Oswald que, em 1943, lançou o Manifesto de Teatro de Estádio $^{11}$.

Essa luta real pelo espaço urbano é material de trabalho incorporado. É o poder de subversão da forma, atribuindo ao teatro uma força sobre humana de existência, de luta por direitos, de arte sensorial, arte do "ao vivo", com uma poética da diversidade, ante um mundo dominado pelas telenovelas pasteurizadas. A visão de Zé Celso é de um teatro de comunicação de massa, de escola de samba, de passagem e, sobretudo, anárquico:

O teatro não pode ser um instrumento de educação popular, de transformação de mentalidade na base do bommeninismo. A única possibilidade é exatamente pela deseducação, provocar o espectador, provocar sua inteligência recalcada, seu sentido de beleza atrofiado, seu sentido de ação protegido por mil e um esquemas teóricos abstratos e que somente o levam a ineficácia (MARTINEZ CORREA, 1998, p.97).

O Teatro Oficina é uma companhia de repertório, ou seja, tem um conjunto de obras teatrais como uma espécie de "escola", um conjunto de conhecimentos e de modos de fazer que podem ser acessados de maneira atemporal. O processo de montagem dos espetáculos pode demorar anos e, depois de concretizado, pode ser reutilizado e ressignificado em remontagens de acordo com o sentido e "jogo" para aquele momento.

Assim foi com "As bacantes"12, texto de Eurípedes (406 a.C.), espécie de reconciliação do autor grego com os ritos ao deus Dionísios. O espetáculo demorou uma década para ser construído, com diversas leituras públicas, sendo montado completo pela primeira vez em 1996. "As bacantes" entrou novamente em cartaz no teatro no final de 2016 , em comemoração aos 20 anos da primeira montagem, digamos,

\footnotetext{
${ }^{11}$ Sobre a relação do grupo com a arquitetura e questões fundiárias e sobre o Teatro de Estádio ver: "Lina Bo Bardi. Teatro Oficina. Oficina Theater (1980-1984)" (MARTINEZ CORREA; ELITO; BARDI, 1999) e artigo de Soledade (2009).

12 Sobre parte do processo de "As bacantes" ver http://www.teatroficina.com.br/plays/5. Último acesso em 02/10/2106. 
definitiva. A tradução do Oficina transfere os conflitos entre Penteu e Dionísios ${ }^{13}$ para a "Grécia Brazyleira"14.

O espetáculo é emblemático para a noção de atuação proposta por Zé Celso, para quem a "quarta parede", a separação entre público e plateia, rompida inicialmente por Brecht, é encarada de maneira radical no Oficina. O Teato, enquanto técnica, se propõe a jogar o espectador em cena, num processo que extravasa a ideia de representação, sendo necessário pensar em "presentação", ou seja, fazer-se presente no aquiagora.

Em uma das cenas mais emblemáticas de "As bacantes”, ele é devorado por Dionísios em cena: o coro avança sobre o público, escolhendo e seduzindo o espectador que será "dilacerado", numa ação catártica e dionisíaca. "As bacantes" é um verdadeiro ritual de iniciação nos mistérios de Elêusis ${ }^{15}$. Os ritos encenados nessa montagem, a partir do testemunho de Eurípedes, também vão ao encontro da ideia do mito fundador da Antropofagia que, para Oswald, foi a deglutição do Bispo Sardinha pelos índios Caetés.

\section{Dos Sertões à Universidade Antropófaga}

O Teatro Oficina foi responsável por um dos maiores acontecimentos do teatro mundial entre 2000 e $2007^{16}$. Um dos momentos áureos desse

\footnotetext{
${ }^{13}$ Para uma oposição entre o pensamento apolíneo e o dionisíaco, ver A origem da tragédia, de Nietzsche (1872).

${ }^{14}$ Assim como Glauber Rocha, Zé também vai subverter o português usando " $z$ " e "y" na sua escrita, como uma espécie de rasura. Nessa Grécia do Oficina, a luta fundiária do grupo e a situação política do país são fios condutores para o subtexto da peça.

${ }^{15}$ Grécia antiga: "Iachos simboliza esta criança no peito da Grande Mãe Deméter; Dionysos seria a força de ser oculta no coração do ser humano e que pode despertar para a verdadeira sabedoria, se guiado por outros que já o conseguiram: os guias iniciáticos. Em Eleusis, duas famílias se destacaram: os Eumólpidas e os Kerikes. Os primeiros encarregavam-se dos cultos: Eumolpes teria recebido sua função da própria Deméter, que lhe confiara os segredos do culto. Diodoro de Sicília afirmou que os eumólpidas derivavam dos sacerdotes egípcios. Na verdade, encontram-se semelhanças entre os cultos a Ísis e os eleusinos, a Deméter" (FLORES, Terezinha M. Vargas. 24/07/2015 Congresso da Associação Junguiana do Brasil 2015. Disponível em:https://opontodentrodocirculo.wordpress.com/2015/07/24/ritos-a-dionisio-osmisterios-de-eleusis/ Acesso em 02/11/2016).

16 Sobre o acontecimento Os sertões, ver http://www.teatroficina.com.br/plays/8 Último acesso em 02/10/2016.
} 
processo pode ter sido a encenação completa de "Os sertões", de Euclides da Cunha, na própria Canudos (BA), em cinco dias de apresentação. Sem dúvida, foi um dos grandes feitos na história das artes no Brasil. Eram mais de 100 pessoas, entre atores, equipe técnica e contrarregras, para cuidar de animais, preparar comidas que faziam parte do espetáculo e realizar a transmissão em tempo real pela internet.

É possível afirmar que o início do processo do "Os sertões" começa em 1969, quando o Oficina estava em cartaz com "Na selva das cidades" (BRECHT, 1995), um marco dentro da companhia, com cenário de Lina Bo Bardi, no qual os atores e as atrizes "destruíam", noite a noite, o próprio teatro. Nesse ano, no rodapé do programa do espetáculo, na última página, o Oficina anunciava seu novo projeto: “Em 70, o Teatro Oficina viajará pela América Latina com Os sertões” (PEIXOTO, 1982, p.86).

Passados mais de 30 anos, o grupo finalmente conseguiu transpor a epopeia de Euclides para o palco, encenando cinco peças: "A terra" (2002), “O homem I" (2003), “O homem II” (2003), “A luta I” (2005) e “A luta II" (2006), totalizando 27 horas de duração. Em 2004, durante o processo, o grupo realizou a saga de se apresentar em Recklinghausen, na Alemanha, cidade que fica no coração da indústria militar alemã, de onde teria saído boa parte das armas que abasteceram o aparato militar em Canudos. Acontecimentos como esse potencializam essa mística do teatro enquanto instrumento de ressignificação de experiências e, no caso desse genocídio fundador da República brasileira, quase que um triunfo do corpo anárquico da companhia incorporado pela força dos sertanejos, da vegetação e do clima da caatinga.

Embora o Teatro Oficina tenha sempre funcionado como uma escola de formação, e basta ver a quantidade de atores e atrizes que passaram pelo teatro nesses 58 anos, é com "Os sertões" que se fortalece a ideia de sistematizar esse conhecimento. Na Alemanha, os holofotes estão na universidade nascente que resultaria na Universidade Antropófaga ${ }^{17}$ :

O teatro Oficina foi da rua Jaceguai para o interior de uma mina, onde os alemães reconstruíram o espaço de Lina Bo Bardi para a apresentação de "Os sertões". Você chega e vê uma imensa faixa amarela na qual está escrito: "Universidade de culturas brasileiras orgiásticas". Fica

${ }^{17}$ Informações completas sobre a Universidade Antropófaga e suas idiossincrasias: www.universidadeantropofaga.org. 
sabendo depois que está no lugar onde foram produzidas as armas que alimentaram a guerra de Canudos (MILAN, $2004)^{18}$.

A ideia de que o teatro é responsável pela formação de sujeitos e por transformações radicais da realidade faz parte do teatro encenado no Oficina. A complexidade de "Os sertões" foi verdadeira universidade para atores e atrizes envolvidos/as, principalmente, os/as que vieram do Movimento Bixigão (2002-2011).

O Bixigão, que começa no ano da estreia de "Os sertões", envolveu o trabalho com crianças do bairro do Bexiga. O bairro é um dos mais tradicionais e populares de São Paulo, como já falado, vítima da especulação imobiliária crescente. É um bairro com forte caráter cultural, passando pela gastronomia, pelo teatro, tendo sido morada de Oswald de Andrade. As crianças foram incorporadas ao espetáculo e, muitas vezes, criaram cenas. Com o livro de Euclides, grande parte dos 60 atuadores do teatro passou a ensinar e a aprender com as crianças, expandindo "consciências do inconsciente" ao obrigar-se a uma reflexão teórico-didática do que estava sendo inventado. É conhecida como fase da "pré primária-dentição" 19 da Universidade:

Esse livro, o mais editado e traduzido do Brasil - e talvez o menos lido -, de qualquer maneira foi a primeira grande interpretação do Brasil, ou dos dois Brazis. Inspirou o aparecimento do Grande sertão: veredas, das interpretações luminosas de Sérgio Buarque de Holanda, Oswald de Andrade, Nelson Rodrigues, Darcy Ribeiro e Glauber Rocha. Era sonho de Lina Bo Bardi montarmos juntos essa obra. Quem atravessa o livro coletivamente, como fez a companhia com os inúmeros atuadores do público de 2000 a 2007, adquire uma Universidade. Nesse processo, o Oficina abriu-se inteiramente para a inclusão social, não por dever ético, mas por desejo e necessidade estética. O povo que vive nas condições que o brazileyro vive tem um grande saber, e quer se apossar dos instrumentos todos da cultura universal sem precisar submeter-se a seus cânones.

\footnotetext{
${ }^{18}$ Festival na Alemanha abraça a doçura orgiástica de "Os Sertões". Folha de S. Paulo, 07/06/2004 Disponível em http://www1.folha.uol.com.br/fsp/ilustrad/fq0706200409.htm Último acesso em $02 / 10 / 2016$.

${ }^{19} \mathrm{O}$ site da Universidade é repleto de palavras específicas para designar fases e partes desse corpo.
} 
(UNIVERSIDADE ANTROPÓFAGA, 2015).

Bairro operário, local periférico no centro da cidade de São Paulo, o Bexiga conta com uma enorme população de migrantes nordestinos, classes populares, sempre em ligação com o grupo. Essa comunidade reunida em torno do fazer teatral, e hoje, para além das bandas do bairro do Bexiga, tem sido a responsável pela permanente renovação da companhia nos últimos anos. É permanente o recrutamento de arquitetos, atores, multimídias, figurinistas, dramaturgos e gente disposta a fazer parte desse rizoma.

O corpo "indisciplinar" da Universidade mantém o caráter anárquico no qual está assentado todo o conhecimento do Oficina, e também a pesquisa em torno do corpo e do seu saber-poder (FOUCAULT, 2002). A produção "anarcadêmica", a "pluriversidade", seu magma e imaginários, compõe esse texto rasurado, essa linguagem cheia de significados a partir da diferança ${ }^{20}$ (DERRIDA, 1991).

Tamanho phoder dessa companhia está traduzido nas impressões de um alemão a respeito da passagem do grupo pelo país, impactado pela antropofagia enquanto conhecimento:

Este teatro-maratona, cujas partes duram um total de quase 24 horas, é na verdade, de extrema atualidade. Mas um teatro total como esse faz suas exigências ao espaço. Toda a área do palco e da platéia foi descaroçada (...) Este palco, que na verdade se resume numa pista, foi inspirado no espaço original do Teatro Oficina em São Paulo: uma área de encenação como o Sambódromo no Rio de Janeiro. Um local adequado para uma "ópera de carnaval" (...) Já no ano anterior o Teatro Oficina apresentara esse épico que tinha só três partes - na Alemanha: no festival Ruhrfestspiele em Recklinghausen. Naquela ocasião, esse teatro da desmedida conseguiu o feito de tirar da reserva o reservado público alemão. Vários espectadores, impelidos pela vivência teatral no próprio corpo, foram levados a seguir o exemplo da nudez dos atores. (...) Trabalho e prazer, seriedade e diversão? Por que é que deveríamos separar essas coisas de uma maneira tão obstinada? Afinal, somente a mistura, a união dos contrários e dos adversários é capaz de transcendência. A antropofagia é a incorporação

20 Tradução de Joaquim Torres Costa e Antônio M. Magalhães para o termo "différance", justificado em nota dos tradutores: "Contudo ao escrevermos diferança talvez não nos limitemos a ceder cegamente às exigências de um texto que a nossa língua não poderia controlar" (p.34). 
do inimigo sagrado. Nem tudo é ruim no canibalismo. Um brasileiro sabe disso. (TEICKE, 2005) ${ }^{21}$.

A Antropofagia, segundo o próprio Zé Celso, se materializou no Teatro Oficina: "A arte da antropofagia de Oswald nos come, distingue e une. Oficina quer sua descriminalização, liberdade de culto, reconhecimento, gratidão, adoração pro lugar e precisa de dinheiro pra sua potencialização" (MARTINEZ CORREA; BARDI; ELITO, 1999, p.49).

\section{Novas práticas e artivismo: morte, rituais e enfrentamento}

Dissidências que afrontam a hegemonia do neoliberalismo, do pensamento e inconsciente colonial heterossexista e do capital. Esse novo pensamento ou a construção de um novo paradigma cultural não está centrado no ideário de "igualdade" da Idade Moderna, mas aposta numa perspectiva das diferenças. Nessa direção, os artivismos das dissidências sexuais e de gênero vão incidir diretamente sobre o tabu e, por isso, inseridas no contexto entre vida e morte. Não apenas a morte do sujeito, da identidade binária através da afronta aos códigos da cisgeneridade e dos poderes hegemônicos, mas também da ameaça a partir da homofobia, lesbofobia e transfobia enquanto aparatos da tecnologia de poder disciplinar.

"A própria função do teatro é trabalhar com o bode expiatório", diz Zé Celso $(1988)^{22}$. O medo de mudança da sociedade e os medos individuais seriam os criadores desses "bodes": "O bode é o marginal, o maconheiro, o homossexual, o pivete. $\mathrm{O}$ teatro trabalha assumindo o lado do bode: na Grécia, ator trágico significava: 'o bode que canta"'. Para o diretor, o teatro enquanto prática e saber desfaz o jogo que determina o bode expiatório. "Na religião, você cultua o bode, o Cristo, para que ele pague o pecado dos outros. No teatro, é exatamente o

\footnotetext{
21 Publicado na ZITTY, revista quinzenal de Berlim, sob a rubrica "Palco" em 20/09/2005. Friedhelm Teicke. Traduzido por Angelika Köhnke, disponível em: http://www.teatroficina.com.br/posts/29. Último acesso em 02/10/2016.

${ }^{22}$ Entrevista para o jornal O Dia, em 10/01/1988.
} 
contrário: você assume o bode para acabar com a necessidade da existência dele".

Essa reflexão do timoneiro do Oficina surge a partir do assassinato brutal de seu irmão, na véspera do Natal de 1987. Luiz Antônio Martinez Corrêa era um dos grandes diretores de teatro de sua época. Dirigiu espetáculos como A ópera do malandro, de Chico Buarque, com Marieta Severo e Elba Ramalho. "O que você espera que aconteça com o assassino de seu irmão?", pergunta uma repórter. Zé Celso responde que quer saber o por quê do crime e diz que a punição para o assassino seria experimentar tudo o que a vida apresenta, ser obrigado a viver tudo que ele tem medo: "Por que o cara é uma entidade oposta à vida. Esta entidade, não o rapaz, tem que ser destruída, deixar de existir. Temos que virar os valores do avesso, porque os valores que dominam é que permitem estes assassinatos. A sociedade tem que jogar luz em cima, saber o que é, para acabar com isto" (MARTINEZ CORREA, 1988).

A fala de Zé Celso a respeito do assassinato do irmão, este artista que criava um saber-poder, capaz de aglutinar pessoas de forma amorosa, envereda para a natureza do teatro que é lidar com tabus sociais:

Esta cena é exemplar: por que uma pessoa dá 80 facadas em outra? O que está projetado nesse rapaz, o que ele tem socialmente no corpo? Ele é símbolo de todas as outras violências. Inclusive o assassinato cultural, porque você não mata apenas a vida da pessoa, mas a possibilidade de ela produzir algo melhor para a sociedade. É uma coisa cultural, por isso tem que haver uma mudança na cultura. A burrice, o lado curupira, o lado estreito, determinam essa violência. Fascismo não é só cara que vai lá e mata, é também quem não quer saber de nada, não quer se envolver em nada. Todo o desejo violento destes é projetado em outras pessoas. A violência maior é a de não querer mudar, de fechar a cabeça nestes tabus. Por isso os crimes têm acontecido com homossexuais artistas: o artista mexe com a vida, dissemina essa insatisfação com a vida levada com gosto de morte (MARTINEZ CORREA, 1988).

Para Zé Celso, o trabalho do bode tem que ser feito onde há o preconceito. "Quem tem que fazer este trabalho, senão as pessoas que lidam com valores, na música, nas roupas, no teatro, na postura?", pergunta (MARTINEZ CORREA, 1988). 
Depois da morte $\mathrm{Lu}(\mathrm{i}) \mathrm{z}^{23}$, todos os anos, no dia 23 de dezembro, às 14h30, o Oficina realiza o espetáculo em cartaz no horário suposto do crime, em memória desse mago que unia as pessoas. Luz! Assim reforça-se o "marco importante de um caminho difícil", essa igreja de onde, sentados, olhamos eletronicamente (em referência a interface tecnológica sempre usada pelo Oficina com suas câmeras e transmissões), "simplicidade e clareza como num nô japonês"24.

E esse ritual não deixa de ser político, no caso do Oficina, que tem optado nessas décadas por textos que sempre fazem uma leitura crítica do Brasil e dos costumes da modernidade. Não é a toa que a ideia de Lina deu subsídio para a criação do conceito "terreiro elektronico", pois há aproximações dentro da estética do Oficina com essa cosmogonia do candomblé e da umbanda. Zé Celso mesmo já afirmou que, durante a ditadura, antes do exílio e da prisão, costumava se esconder nos terreiros.

\section{Considerações finais}

Atualmente, a trans Wallace Ruy integra o elenco da companhia. Em agosto de 2016, o Teatro Oficina abrigou o espetáculo Divas florescer, com moradoras do único centro de acolhida voltada para o público no Brasil: o Centro de Acolhida Especial para Mulheres Transexuais, da Prefeitura Municipal de São Paulo ${ }^{25}$

Em 1985, a trans e ativista Cláudia Wonder (1955-2010) participou de uma leitura de "O homem e o cavalo", de Oswald de Andrade, sob direção de José Celso Martinez Correa. Na ocasião, a atriz ficava nua em determinada cena, expondo, aos olhares binários e heterossexistas

\footnotetext{
${ }^{23} \mathrm{Na}$ escrita rasurada de Zé Celso, o “i” aparece entre parênteses de modo que o nome do irmão também seja lido como luz.

${ }^{24}$ Lina Bo Bardi: “(...) O Oficina não é o portal da Catedral de Colônia do fim do Século XVIII, mas é o marco importante de um caminho difícil (...) Em termos de arquitetura, A Tempestade destruiu tudo e o Oficina vai agir de novo. Na base da maior simplicidade e da maior atenção aos meios científicos da comunicação contemporânea. É tudo. Olhar eletronicamente sentados numa cadeira de igreja" (MARTINEZ CORREA; BARDI; ELITO; 1999).

25 O centro foi criado na gestão do prefeito Fernando Haddad (PT): https://goo.g1/IDScuc. Último acesso em 02/10/2016.
} 
da plateia, a inconformidade com a matriz da heteronorma. O fato é brilhantemente narrado pela própria Wonder no documentário dirigido por Dácio Pinheiro ${ }^{26}$. A performance libera a arte do ilusionismo e aquela visualidade, para além da discursividade, mostra que a estética dos sujeitos artistas, do performer, produz potências, tanto em termos de significação, quanto afetivas e libertárias que o (des) representam ou "presentam", no sentido de estar presente.

Se a performance obedece a uma desconstrução do corpo que estava fetichizado pela pintura, a escultura e a literatura (BLANCA, 2016), o Oficina trabalha com essa ideia a partir do "inxorcismo" ou da ideia da "alma virar corpo", como citado em um dos cânticos de "As bacantes". Há centralidade e consciência de que as mudanças operam pelo próprio corpo que é a própria intersecção e encruzilhada dos saberes disciplinares ou do saber-poder.

Por fim, por trás da emergência desses movimentos dissidentes está um tensionamento com o cartesianismo e a busca da concretização da Política do Desejo, contrariando Freud, e em termos deleuzianos, entendendo o desejo não como falta, mas como potência.

O Teatro Oficina, enquanto criador dessa universidade antropófaga que condensa de maneira não cartesiana um saber-poder desses atletores, é bom exemplo de re(x)istência e, o mais importante, um dos mentores e emissores da criação de novas práticas. Essa nova cartografia de representações, com sua linguagem potente e impactante, tem a capacidade de fazer o corpo ser afetado pelo corpo vivo do mundo (ROLNIK, 1989), criando novas subjetividades, abrindo fluxos desejantes.

Na fecundação e cultivo dessa prática milenar de representação que é o Teatro, o Uzyna Uzona parece buscar o encontro de uma experiência do sujeito, a experiência como ser vivo, que leva ao encontro do Cosmo, numa recuperação da visão goethiana (SUZUKI, 2005). É a crença de que os poetas podem dar a sua contribuição para a construção do mundo,

\footnotetext{
${ }^{26}$ MEU AMIGO Cláudia. Produção de Chica Mendonça. São Paulo: Festival Filmes, 2009. Digital. 87 min.
} 
para além das raízes únicas do cânone ocidental, no a-e-i-u-o ${ }^{27}$ de Rimbaud (1895) que tanto inspirou os cânticos dos ritos de Baco.

Precisamos identificar as violências epistemológicas, sexuais e científicas que contribuem para as hierarquizações. Como diz Zé Celso (1988), tudo o que significa mudar, pular a cerca, sair do limite, dá medo. Assim, temos que ser verdadeiros brigadistas e defensores das expressões dissidentes, abjetas, não normatizadoras, sempre procurando garantir que elas possam ser mostradas, como condição de contribuir para a desprogramação desse inconsciente colonial e para assimilação de novas práticas.

Visibilizar essas práticas artivistas que vão ao encontro de uma perspectiva queer, de desestabilização, contribuem para a identificação dos conflitos políticos, científicos e culturais. Reinterpretar os acontecimentos, vasculhar de maneira arqueológica tudo que está submerso e oculto pela hegemonia vai contribuir para a transformação da ciência ou, como sugere Rosa Maria Blanca (2016), de maneira radical, para o seu desaparecimento.

Em recente entrevista ${ }^{28}$, Zé Celso (2016) se mostra em intensa atividade artística aos 79 anos, rompendo o tabu da velhice e brincando com temas urgentes:

Eu viajei tanto na minha vida, de ácido, peiote, tudo, aí eu li o livro do [xamã] Davi Kopenawa e ele lembra todas as viagens dele, que ditou em ianomâmi para um etnólogo francês, Bruce Albert. E saquei, agora é que tive essa percepção, do que é, como um ritual, como Bacantes: Quem passa sofre uma transformação. Vira do avesso a cultura.

A indianidade presente em seus espetáculos e a autodefinição de José Celso Martinez Corrêa como uma espécie de xamã revelam essa "metodologia indisciplinar antropofágica", uma prática imbricada com as culturas, para além da adjetivação "brasileira", mas uma cultura

27 "A noir, E blanc, I rouge, U vert, O bleu: voyelles,/ Je dirai quelque jour vos naissances latentes:/ A, noir corset velu des mouches éclatantes/ Qui bombinent autour des puanteurs cruelles" Arthur Rimbaud (1895, p.7).

${ }^{28}$ O vídeo da entrevista para a Revista Serafina, da Folha de S. Paulo, para o jornalista Nelson de Sá, pode ser visto aqui: https://goo.gl/TjZegC. Último acesso em 02/10/2016. 
antropológica, antropófaga, redentora e expurgadora dos males da modernidade, da civilização e da colonização.

\section{Referências}

ANDRADE, Oswald. O Santeiro do Mangue e Outros Poemas. Rio de Janeiro: Ed. Globo, 2012.

ARTAUD, Antonin. Heliogabalo ou o anarquista coroado. Lisboa: Assírio \& Alvim, 1991.

BLANCA, Rosa Maria. Performance entre a arte, identidade, vida e morte. Cad. Pagu [online]. 2016, n.46, p.439-460. Disponível em http://www.scielo.br/scielo.php?script=sci_arttext\&pid=S0104-

83332016000100439\&lng=es\&nrm=iso Último acesso em 2710/2016.

BRECHT, Bertold. Teatro Completo - Vol 1. Rio de Janeiro: Paz e Terra, 1995.

COLLING, Leandro. Que os outros sejam o normal - tensões entre movimento LGBT e ativismo queer. Salvador: EDUFBA, 2015.

CYSNEIROS, Adriano $\mathrm{B}$. Da transgressão confinada às novas possibilidades de subjetivação: resgate e atualização do legado Dzi a partir do documentário Dzi Croquettes. Dissertação de mestrado nãopublicada. Universidade Federal da Bahia, Programa Multidisciplinar de Pós-graduação em Cultura e Sociedade, 2014, Salvador, Brasil.

DERRIDA, Jacques. A Diferença. In: Margens da filosofia. CampinasSp: Papirus, 1991, p. 33-63.

DE SÁ, Nelson. “À beira dos 80, Zé Celso faz filme e peças, por amor e para pagar contas". In: Revista Serafina. Jornal Folha de S. Paulo, 25/09/2016. Disponível em: http://www1.folha.uol.com.br/serafina/2016/10/1815984-a-beira-dos80-ze-celso-faz-filme-e-pecas-por-amor-e-para-pagar-contas.shtml Último acesso em 05/11/2016.

FLORES, Terezinha M. Vargas. Ritos a Dionísio: os mistérios de Elêusis. Apresentado no Congresso da Associação Junguiana do Brasil, Belo Horizonte, 6-9 de setembro de 2000. Disponível em https://opontodentrodocirculo.wordpress.com/2015/07/24/ritos-adionisio-os-misterios-de-eleusis/ Último acesso em 02/10/2016. 
FOUCAULT, Michel. “Aula 17/03/1976”. In: Em defesa da sociedade. São Paulo: Martins Fontes, 2002, p. 285-315.

GLISSANT, Édouard. Introdução a uma poética da diversidade. Juiz de Fora: Editora UFJF, 2005. 176 p.

LESSA, Patrícia. Visibilidades y ocupaciones artísticas en territorios físicos y digitales. PADRÓS, Núria; COLLELLDEMONT, Eulàlia; SOLER, Joan. Actas del XVIII Coloquio de Historia de la educación: arte, literatura y educación. v.1, Vic: Espanha: Editora da UniVic, 2015, p.211-224.

MARTINEZ CORREA, José Celso. Primeiro ato: cadernos, depoimentos, entrevistas (1958-1974). Org. Ana Helena Camargo de Stall. São Paulo: Editora 34, 1998.

. "O artista é a arma da revolução". Entrevista para

Eliane Azevedo. O Dia 10/01/1988. Disponível em: http://www.teatroficina.com.br/posts/141 Último acesso em 27/10/2016.

MARTINEZ CORREA, José Celso. BARDI, Lina Bo; ELITO, Edson. Teatro Oficina 1980-1984. Lisboa: Printer Portuguesa S.A., 1999.

MILAN, Betty. Festival na Alemanha abraça a doçura orgiástica de "Os Sertões". Folha de S. Paulo, 07/06/2004. Disponível em http://www1.folha.uol.com.br/fsp/ilustrad/fq0706200409.htm Último acesso em 02/10/2016.

MISKOLCI, Richard. A Teoria Queer e a Sociologia: o desafio de uma analítica da normalização. Sociologias, Porto Alegre, ano 11, n 21, jan/jun.2009, p.150-182.

MOORE, Rowan. The 10 best theatres. The Guardian, Londres, 11 dez. 2015. Disponível em https://goo.gl/1RaALs. Acesso em $10 / 12 / 2016$.

NODARI, Alexandre. "A transformação do tabu em totem: notas sobre (um)a fórmula antropofágica". In: MARQUES, Pedro Neves. The Forest and the School. How to sit at the dinner table? Berlim: Archive Books, 2014.

OLIVA, César; MONREAL, Francisco Torres. Historia básica del arte escénico. Madrid: Edit. Cátedra, 1990. 
PEIXOTO, Fernando. Especial: Teatro Oficina. Org. Fernando Peixoto. Revista Dyonisos. Rio de Janeiro: Ministério da Educação e Cultura/ SEC - Serviço Nacional de Teatro, Janeiro de 1982. N.26.

RAPOSO, Paulo. "Artivismo": articulando dissidências, criando insurgências. Cadernos de Arte e Antropologia, volume 4, número 2, 2015, pp. 3-12.

RIMBAUD, Arthur. Poésies complètes. Avec préface de Paul Verlaine et notes de l'éditeur. Paris: L. Vanier, 1895 Disponível em: http://gallica.bnf.fr/ark:/12148/btv1b86108403/f34.vertical Último acesso em 05/11/2016.

ROLNIK, Suely. "Cartografia ou como pensar com o corpo vibrátil". In: Cartografia sentimental - transformações contemporâneas do desejo. São Paulo: Editora Estação Liberdade, 1989.

SANT'ANA, Tiago dos Santos. Outras cenas do queer à brasileira: o grito gongadeiro de Jomard Muniz de Britto no cinema da Recinfernália. Dissertação de mestrado não-publicada. Universidade Federal da Bahia, Programa Multidisciplinar de Pós-graduação em Cultura e Sociedade, Salvador, 2016, Brasil.

SOLEDADE, Viviane. Teatro Oficina Uzyna Uzona: tensão entre o interior e o exterior. Rio de Janeiro. Revista Eletrônica de críticas e estudos teatrais, 10/04/2009. Disponível em: http://www.questaodecritica.com.br/2009/04/teatro-oficina-uzynauzona-tensao-entre-o-interior-e-o-exterior/ Último acesso em 28/10/2016.

SUZUKI, M. “A ciência simbólica do mundo". In: NOVAES, A. (Org). Poetas que pensaram o mundo. São Paulo: Cia das Letras, 2005, p.205.

UNIVERSIDADE ANTROPÓFAGA. Pré-Primária-Dentição. [s.d.] 2015. Disponível em: http://www.universidadeantropofaga.org/preprimaria-denticao Acesso em 02/11/2016

VERGUEIRO, Viviane. Por inflexões decoloniais de corpos e identidades de gênero inconformes: uma análise autoetnográfica da cisgeneridade como normatividade. Dissertação de mestrado nãopublicada. Universidade Federal da Bahia, Programa Multidisciplinar de Pós-graduação em Cultura e Sociedade, Salvador, 2016, Brasil.

Recebido em 14/11/2016

Aprovado em 27/12/2016 